\title{
REKRUTMEN KARANG DI KAWASAN WISATA LOVINA
}

\author{
I Nyoman Dodik Prasetia ${ }^{1}$ \\ ${ }^{1} J u r u s a n$ Budidaya Kelautan, FMIPA, Universitas Pendidikan Ganesha \\ Singaraja, Indonesia \\ e-mail: dodik_prasetia@yahoo.com
}

\begin{abstract}
Abstrak
Rekrutmen karang merupakan masuknya individu karang baru ke populasi terumbu karang karena reproduksi atau migrasi. Kemampuan rekrutmen karang adalah kemampuan dari suatu koloni individual atau suatu sistem terumbu karang untuk mempertahankan diri dari dampak lingkungan, menjaga kemampuan pemulihan dan perkembangan. Penelitian dilaksanakan pada bulan Maret sampai Oktober 2011, bertujuan mengetahui pola penyebaran planula karang, jenis, kelimpahan dan pola bertahan hidup planula karang serta kondisi fisik, kimia, dan biologis perairan. Penelitian dilakukan pada kedalaman 5 meter dengan 3 buah rak penelitian pada setiap stasiun penelitian. Sebuah rak terdiri dari 24 buah substrat dengan 4 posisi yang berbeda terhadap arus. Planula karang yang ditemukan terdiri dari jenis 9 karang dan 109 individu. Planula karang ditemukan pada semua stasiun penelitian dengan jumlah terbesar pada Stasiun 3 sebanyak 59 individu. Kondisi fisik, kimia, dan biologis perairan di Lovina relatif masih mendukung pertumbuhan dan perkembangan planula karang untuk dapat menjadi koloni karang.
\end{abstract}

Kata kunci: planula karang, rekrutmen karang, terumbu karang

\begin{abstract}
Coral recruitment is the entry of new individuals to coral reefs populations due to reproduction or migration. Coral recruitment capabilities are the ability of an individual colony or coral reef systems to defend against environmental impacts, recovery and development capabilities. The experiment was conducted in March until October 2011, aims to determine the pattern of spread of coral planula, species, abundance and patterns of coral planula survive as well as physical, chemical, and biological. The study was conducted at a depth of 5 meters by 3 pieces of rack of research on each research station. A rack consists of 24 pieces of the substrate with 4 different positions to the current. Coral planulas are found to be composed of nine coral species and 109 individuals. Coral planula found in all the research station with the largest amount in 3 of 59 individual stations. Physical, chemical, and biological in Lovina coastal area relatively still support the growth and development of coral planula to be a coral colony.
\end{abstract}

Keywords: coral planula, coral recruitment, coral reef 


\section{PENDAHULUAN}

Kawasan Lovina merupakan salah satu tujuan pariwisata bahari yang sangat terkenal di Bali. Daya tarik utama Kawasan Lovina adalah keindahan pesisir dan laut serta ditunjang oleh keberadaan organismeorganisme laut yang eksotik. Keberadaan aktivitas pariwisata ini memberikan dampak secara langsung maupun tidak langsung terhadap kondisi ekosistem terumbu karang di Kawasan Lovina.

Terumbu karang Lovina secara umum dikategorikan sebagai terumbu karang tepi (fringing reefs) yang merupakan terumbu karang yang hidup disepanjang pantai, meskipun di beberapa titik pengamatan ditemukan tipe terumbu penghalang (barrier reef) yang berupa atol (Prasetia, 2010). Formasi terumbu karang tepi memiliki keuntungan dalam proteksi daratan dari ancaman abrasi dari energi gelombang dan potensi biota yang berasosiasi di dalamnya. Keuntungan ini juga memberikan dampak negatif terhadap kelestarian ekosistem terumbu karang karena mudah terdegradasi oleh aktivitas manusia di daratan.

Penelitian Prasetia Tahun 2010, menunjukkan kondisi penutupan karang hidup di Kawasan Lovina yang meliputi Desa Tukad Mungga, Anturan, Baktiseraga, Banyuasri, Anturan dan Kalibukbuk berkisar antara 18 sampai $44 \%$ penutupan karang hidup dengan kategori buruk sampai sedang. Dengan struktur komunitas terumbu karang Kawasan Lovina memiliki formasi Acropora, Non Acropora, Soft Coral, dan Sponges. Kelompok Acropora umumnya berbentuk branching, digitate, submassive, kelompok Non Acropora dengan lifeform: branching, massive, encrusting, submassive, foliose dan mushroom.
Penutupan karang hidup dengan nilai kurang dari $44 \%$ menunjukkan kondisi yang mengkhawatirkan terhadap keberlangsungan Kawasan Lovina sebagai sebuah objek wisata bahari. Hal ini terjadi karena keindahan dan kelestarian ekosistem terumbu karang menjadi menu utama yang dijual obyek wisata Lovina sebagai daya tarik kedatangan wisatawan. Jika hal ini terus berlanjut bukan tidak mungkin Kawasan Wisata Lovina akan ditinggalkan wisatawan karena hilangnya organisme organisme laut eksotik seiiring dengan semakin menurunnya kelestarian ekosistem terumbu karang.

Secara alami karang dapat membentuk terumbu dengan melakukan reproduksi baik secara seksual dan aseksual. Secara seksual karang akan mengalami masa kritis dalam daur hidupnya saat pelepasan planula untuk mencari subsrat yang optimal untuk kelangsungan hidupnya. Jika hal ini dapat terjadi dengan baik dan karang menemukan tempat dan subsrat yang tepat maka karang akan dapat tumbuh secara optimal. Sehingga diperlukan suatu kajian mendalam tentang rekrutmen karang di Kawasan Lovina dalam kaitannya dengan proses alamiah planula memulai hidupnya.

\section{METODE}

Penelitian dilaksanakan di Kawasan Pesisir Lovina, selama 8 bulan yaitu Maret sampai Oktober 2011.

Penelitian ini menggunakan dua sumber data yaitu data primer dan data sekunder. Data primer berupa prosentase penutupan karang, kelimpahan jenis ikan karang, kondisi fisik dan kimia perairan, kelimpahan jenis jouvenile karang, analisa perlakuan subsrat dan posisi yang berbeda.

Data sekunder merupakan data yang diperoleh dari: profil kawasan pesisir, data 
sosial ekonomi, peta pesisir, buku acuan, laporan-laporan, serta penelitian-penelitian yang pernah dilakukan di Kawasan Pesisir Lovina

Penelitian rekrutmen karang menggunakan subsrat buatan yang berukuran $10 \times 10 \mathrm{~cm}$ yang diletakkan pada rak penelitian, dengan posisi dalam rak yang diasumsikan dapat mewakili adaptasi karang terhadap arus.

\section{Prosedur Penelitian}

Penelitian dilaksanakan dengan diawali dengan pengamatan kondisi umum ekosistem terumbu karang di kawasan ini dengan menggunakan metode Manta Tow Survey (English et al,1994), metode ini merupakan observasi terhadap suatu komunitas terumbu karang dalam skala yang luas dalam waktu yang singkat.

Penelitian rekrutmen karang dilakukan dengan pengamatan dan identifikasi rekrutmen karang sesuai dengan metode English, et al (1994). Pengamatan ini dilakukan pada kedalaman 5 meter, dengan menggunakan 3 buah rak penelitian pada setiap stasiun penelitian. Satu buah rak penelitian yang dilengkapi 24 buah subsrat yang ditempatkan pada 4 posisi yang berbeda. Subsrat memiliki berukuran 10X10 $\mathrm{cm}$ dengan bahan dasar pembuatan mengikuti subsrat alami karang.

Pengamatan dilakukan selama 6 bulan pengamatan terhadap pertumbuhan dan perkembangan planula pada subsrat tersebut. Parameter yang diamati dalam penelitian rekrutmen karang adalah: Jenis planula karang yang menempel pada subsrat; Kelimpahan planula karang pada subsrat; dan Perkembangan planula karang pada setiap posisi subsrat;

Metode Line Intercept Transect dilaksanakan untuk mengkaji komunitas bentik berdasarkan karakteristik life form terutama morfologi dari komunitas terumbu karang, sehingga dapat diketahui keanekaragaman jenis karang di daerah tersebut. Pengamatan dengan Line Intercept Transect dilakukan dengan SCUBA diving pada kedalaman $3 \mathrm{~m}$ dan 10 $\mathrm{m}$ (English et al, 1994).

Penelitian terhadap kondisi fisik yang diukur dan diamati langsung di lapangan pada masing-masing stasiun penelitian adalah: Suhu, Kecepatan arus,Kekeruhan dan Sampah atau tumpahan minyak.

\section{Analisa Data}

Data rekrutmen karang dianalisa dengan pendekatan deskriptif kuantitatif. Penempelan planula pada subsrat menunjukkan pertumbuhan dan perkembangan planula pada masing-masing stasiun terhadap kondisi lingkungan. Laju perkembangan karang menunjukkan jenis, jumlah, dan kelimpahan perkembangan planula karang pada posisi substrat yang berbeda.

Analisa data dengan menggunakan metode Line Intercept Transect dilakukan dengan memperhatikan prosentase penutupan suatu kategori pada transek garis sepanjang 50 meter. Dengan pembagian kategori penutupan karang sesuai dengan pendekatan Gomez dan Yap (1988) adalah:

$$
\begin{array}{ll}
75-100 \% & \text { Sangat baik } \\
50-75 \% & \text { Baik } \\
25-50 \% & \text { Sedang } \\
0-25 \% & \text { Buruk }
\end{array}
$$

Hasil penutupan karang hidup yang tinggi menunjukkan keberadaan terumbu karang di daerah tersebut dalam kondisi sehat. Dan akan ditunjang oleh tingginya indeks keanekaragaman di daerah tersebut. 


\section{HASIL DAN PEMBAHASAN}

Terumbu karang Lovina secara umum dikategorikan sebagai terumbu karang tepi (fringing reefs) yang merupakan terumbu karang yang hidup disepanjang pantai, meskipun di beberapa titik pengamatan ditemukan tipe terumbu penghalang (barrier reef) yang berupa atol.

Formasi terumbu karang tepi memiliki keuntungan dalam proteksi daratan dari ancaman abrasi dari energi gelombang dan potensi biota yang berasosiasi di dalamnya. Keuntungan ini juga memberikan dampak negatif terhadap kelestarian ekosistem terumbu karang karena mudah terdegradasi oleh aktivitas manusia di daratan.

Pengamatan dengan manta tow survey menunjukkan keberadaan terumbu karang kurang lebih 50 meter dari garis pantai, sepanjang pantai Desa Kalibubuk, Anturan, Tukad Mungga, Pemaron, Baktiseraga, dan Banyuasri. Kategori penutupan karang hidup di Kawasan Lovina menggunakan manta tow survey menunjukkan kategori antara buruk sampai baik.

Kondisi penutupan karang hidup dengan kategori 1 sampai 3 terpantau di kawasan pantai Desa Tukad Mungga, Anturan, Baktiseraga, dan Banyuasri, sedangkan kategori 2 sampai 3 secara umum dapat dijumpai di Desa Anturan dan Kalibukbuk.

Parameter karang keras yang diamati di beberapa stasiun pengamatan menunjukkan adanya nilai Indeks Mortalitas atau kematian karang yang cukup tinggi. Nilai mortalitas yang tinggi, menurut Gomez et al. (1994), menunjukkan kondisi karang batu sudah mendapat tekanan yang cukup besar. Hal ini terlihat dari banyaknya rubble atau karang yang berupa serpihan-serpihan kecil di lokasi penelitian, dan selain itu terlihat adanya karang batu yang telah mati dan ditumbuhi alga.
Tingginya tekanan terhadap ekosistem terumbu karang di Kawasan Lovina mengakibatkan tidak optimalnya pertumbuhan dan perkembangan individu karang di kawasan ini. Tekanan ini berasal dari aktivitas manusia sebagai pemanfaat pesisir dan alam itu sendiri. Aktivitas manusia terdiri dari pembangunan yang tidak berwawasan kelestarian lingkungan, kegiatan perikanan yang merusak, aktivitas pariwisata yang tidak ramah lingkungan, dan masuknya bahan pencemar ke badan perairan.

Menurut Burke, et al. (2002), ekosistem terumbu karang yang ada di wilayah Asia Tenggara merupakan yang paling terancam di dunia. Besarnya ketergantungan manusia terhadap sumberdaya laut di seluruh Asia Tenggara telah menyebabkan eksploitasi yang berlebih sehingga banyak terumbu karang yang terdegradasi, khususnya di dekat pusat kepadatan penduduk. Sekitar $70 \%$ penduduk di kawasan ini hidup di sekitar $50 \mathrm{~km}$ pesisir.

Penyebab utama kerusakan terumbu karang adalah oleh aktivitas manusia (anthropogenic impact), misalnya melalui tangkap lebih (over-exploitation) terhadap hasil laut, penggunaan teknologi yang merusak, seperti potassium cyanide, bom ikan, muro ami dan lain-lain (Anonim, 2002). Ditinjau dari segi ekonomi dan sosial, pengerusakan karang dapat menurunkan pendapatan dan kesejahteraan masyarakat. Karena dengan rusaknya ekosistem terumbu karang maka akan berdampak terhadap penurunan minat pengunjung ke daerah tersebut.

Daerah aliran sungai di Kawasan Lovina yang pada waktu penghujan membawa sedimen ke perairan merupakan faktor alam yang turut mengendalikan pertumbuhan karang. Sedimentasi secara 
langsung dan tidak langsung mempengaruhi pertumbuhan karang karena banyaknya energi yang dikeluarkan untuk menghalau sedimen ini agar tidak ke permukaan polip (Pastorok dan Bilyard, 1985 dalam Supriharyono 2000). Meningkatnya sedimen akan mematikan karang dan tambahan unsur hara dapat menyebabkan karang ditumbuhi alga yang menjadi pesaing karang dalam hidup (Anonim, 2001). Hal ini disebabkan sedimen yang berlebihan dapat mematikan karang, karena oksigen terlarut dalam air tidak dapat berdifusi masuk ke dalam polip karang (Dahuri, et al. 1996)

\section{Struktur Komunitas Terumbu Karang Kawasan Lovina}

Pengamatan dengan line intercept transect dilakukan pada 3 titik stasiun penelitian yang diperoleh dari pengundian hasil pementaan dengan menggunakan manta tow survey. Hal ini dilakukan dengan mempertimbangkan keterwakilan setiap wilayah pengamatan, sehingga diharapkan hasil yang didapat mewakili kondisi ekosistem terumbu karang di kawasan penelitian.

Secara umum penelitian dengan line intercept transect menunjukkan kondisi terumbu karang berkisar antara 18 sampai $44 \%$ penutupan karang hidup dengan kategori buruk sampai sedang. Hal ini menunjukkan hasil yang tidak jauh berbeda dengan pengamatan menggunakan manta tow survey.

Struktur komunitas terumbu karang di Kawasan Lovina memiliki formasi Acropora, Non Acropora, dan soft coral. Kelompok Acropora umumnya berbentuk branching, tabulate dan submassive, kelompok Non Acropora dengan lifeform: branching, massive, encrusting, submassive, foliose dan mushroom
Struktur komunitas terumbu karang di Stasiun 1 terdiri dari kelompok Acropora branching yaitu karang berbentuk bercabang seperti ranting pohon, seperti: Acropora palmata, A. Formosa. Kelompok Acrophora yang lain adalah Acrophora digitate yaitu karang berbentuk percabangan rapat dengan cabang seperti jari-jari tangan, seperti jenis: $A$. humilis, $A$. digitifera dan $A$. gemmifera, meskipun dengan jumlah yang relatif tidak banyak. Stasiun 1 yang terletak di Desa Pemaron menunjukkan penutupan karang hidup $21 \%$ dengan karang mati 59\% yang terdiri dati kelompok dead coral dan dead coral with algae.

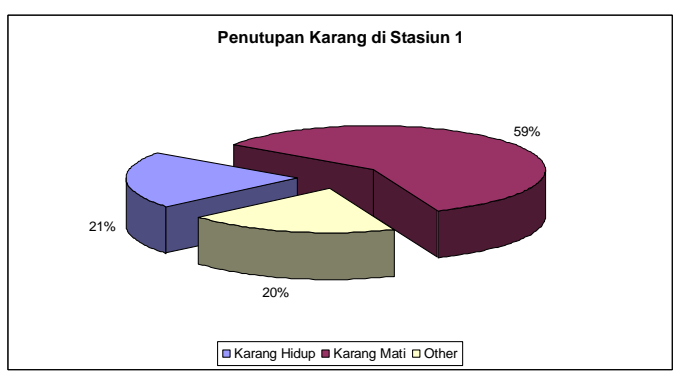

Gambar 1. Kondisi Karang di Stasiun 1

Keberadaan coral massive di stasiun ini sangat dominan dengan penutupan mencapai $14.46 \%$, merupakan karang berbentuk seperti batu besar yang padat. Keberadaan coral massive diasumsikan sebagai pola bertahan hidup karang untuk membentuk koloninya. Adaptasi bentuk seperti otak ini menguatkan posisi karang pada perairan yang jernih dan arus yang relatif keras. Hal ini mengindikasikan kondisi perairan yang relatif tenang dengan tingkat visibilitas yang rendah dan subsrat cenderung bersedimen.

Penutupan karang mati dan karang mati yang ditumbuhi alga sebanyak 59\%, menunjukkan tingginya tingkat tekanan yang dihadapi ekosistem terumbu karang di 
Stasiun 1. Tekanan lebih dominan dikarenakan adanya aliran sungai di kawasan, yang pada saat hujan membawa serta sedimen ke daerah terumbu karang. Faktor kedua yang mempengaruhi adalah aktivitas manusia berupa penangkapan ikan yang merusak pada masa lalu yang mengakibatkan karang harus mengalami proses pemulihan.

Keberadaan ikan karang yang ditemukan di Stasiun 1 berjumlah 100 individu yang terdiri dari 14 jenis ikan karang. Ikan jenis Pseudanthias dispar, Pomacentrus coelestis, dan Chromis analis merupakan ikan yang paling banyak dijumpai, merupakan ikan-ikan indikator kurang baiknya ekosistem terumbu karang suatu perairan.

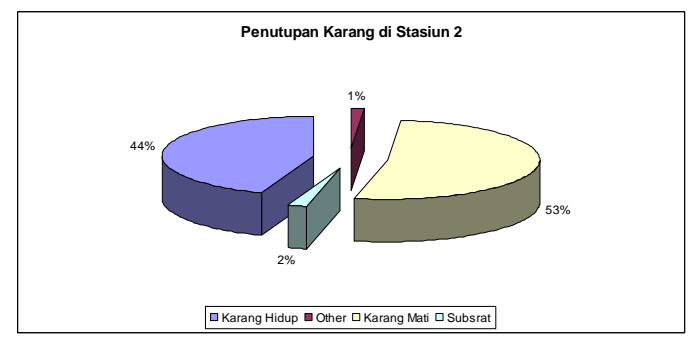

Gambar 2. Kondisi Karang di Stasiun 2

Stasiun 2 yang terletak di kawasan Pantai Tukad Munda menunjukkan nilai penutupan karang hidup 44\%, dengan penutupan karang mati $53 \%$, dengan kategori sedang. Kelompok Acropora yang ditemukan dari kelompok branching dan submassive, Acropora Submassive adalah karang yang percabangannya beberntu gada atau lempeng dan kokoh, seperti Acropora palifera.

Kawasan Tukad Munda memiliki karakteristik yang hampir sama dengan Desa Pemaron dengan aliran sungai aktif maupun tidak aktifnya memberikan kontribusi sedimentasi mengakibatkan kurang optimalnya pertumbuhan dan perkembangan karang utnuk membentuk terumbu. Hal ini mengakibatkan tingginya penutupan karang mati dan karang mati beralga sebesar $53 \%$.

Stasiun 2 yang terletak di kawasan Pantai Tukad Munda menunjukkan nilai penutupan karang hidup 44\%, dengan penutupan karang mati $53 \%$, dengan kategori sedang. Penutupan karang lunak yang ditemukan di kawasan ini mengindikasikan terus bertumbuh dan perkembangnya ekosistem terumbu karang. Hal ini memberikan hararapan yang baik jika kondisi lingkungan tetap terjaga, maka karang akan terus mengalami recovery atau penutupan kembali karang hidup. Karang lunak merupaka salah satu indikator terjadinya recovery suatu ekosistem terumbu karang.

Jenis sponges yang ditemukan di kawasan ini adalah Theonella cylindrical, Xestospongia testudinaria, Haliclona sp, dan Desmapsamma sp. Struktur tubuh sponges yang sederhana dan berongga-rongga berfungsi sebagai peryaring, sehingga di sekitarnya periran lebih jernih. Sponges di kawasan perairan berfungsi sebagai filter yang efektif dengan struktur yang sederhana (Allen and Roger, 1999).

Ikan karang yang berasosiasi dengan terumbu karang ditemukan 29 jenis dengan 390 individu. Jenis Chromis analis, Pseudhantias dispar, $P$. bicolor, $P$. Squamipinnis, dan Pomacentrus coelestis merupakan jenis yang paling sering dijumpai dalam pengamatan ini. Menurut Warner (1984), ikan-ikan dari family Pomacentridae merupakan ikan territori dan planktivora biasa membentuk territorial pada karang bercabang

Kerusakan terumbu karang di Stasiun 3 diindikasikan terjadi karena tingginya 
aktivitas pariwisata di kawasan ini. Atraksi melihat lumba-lumba, snorkling, dan diving merupakan aktivitas yang bersentuhan langsung dengan ekosistem terumbu karang. Hal ini mengakibatkan pertumbuhan dan perkembagan karang mengalami tekanan yang besar, sehingga diperlukan kebijakan untuk mengatasinya.

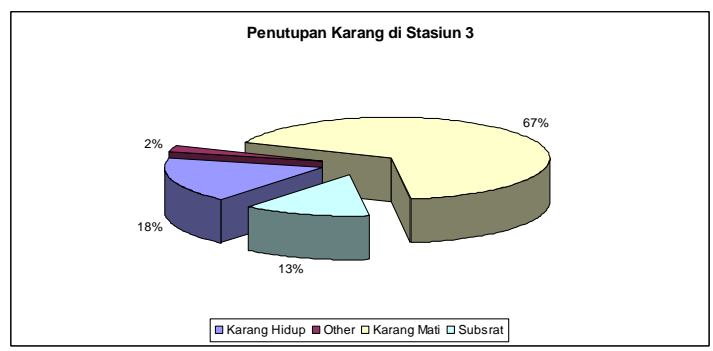

Gambar 3. Kondisi Karang Stasiun 3

Struktur komunitas karang Stasiun 3 meliputi kelompok Acropora Submassive, dan bukan kelompok acropora yang terdiri dari Coral Branching, Coral Encrusting, Coral Massive, Coral Submaasive, dan Coral Mushroom. Coral Mushroom ditemukan secara soliter berbentuk seperti jamur dan berasal dari jenis Fungia sp.

Stasiun 3 yang terletak di kawasan Desa Kalibukbuk yang merupakan jantungnya Kawasan Lovina menunjukkan nilai penutupan karang mati $67 \%$ dengan penutupan karang hidup $18 \%$, dikategorikan sebagai kriteria buruk. Tingkat kerusakan terumbu karang sangat berkaitan dengan penutupan karang mati dan pecahan / patahan karang.

Indikasi yang dipakai bahwa suatu kawasan mengalami kerusakan pada terumbu karangnya adalah: penutupan pecahan / patahan karang (rubble) dan keberadaan alga. Rubble merupakan bentuk dari patahan-patahan karang yang tidak beraturan yang dapat diakibatkan oleh bencana alam, penggunaan bahan peledak untuk mencari ikan, penambangan karang untuk bahan bangunan, pembuangan jangkar, dan aktivitas manusia lainnya yang merusak. Alga merupakan salah satu kompetitor hidup bagi terumbu karang, alga akan sangat sulit untuk hidup dan tumbuh di atas terumbu karang yang baik.

Keberadaan karang lunak menjadi indikasi terjadinya recovery di ekosistem terumbu karang Stasiun 3, karang lunak merupakan kelompok karang pioneer yang akan tumbuh di daerah baru atau yang dulunya pernah terdapat terumbu.

Aktivitas penangkapan ikan yang relatif tidak ada di kawasan ini mengakibatkan jumlah ikan ditemukan dalam kualitas maupun kuantitas yang lebih besar dari stasiun penelitian yang lainnya. Jumlah ikan yang ditemukan sebanyak 755 individu, dari 31 jenis ikan karang yang berassosiasi dengan terumbu.

Jenis Pseudanthias dispar, $P$. bicolor,dan Chromis analis merupakan jenis yang masih dominan di kawasan ini. Keberadaan jenis Zanclus canescens atau moorish idol merupakan ikan indikator sehatnya suatu ekosistem terumbu karang.

\section{Rekrutmen Karang Jenis planula karang}

Secara umum jenis planula karang yang teramati menunjukkan keseragaman jenis di 3 stasiun penelitian. Kehadiran Acropora millepora, Acropora tenuis, Montipora digitata, Pocillopora damicormis, dan Stylophora pistillata ditemukan di semua stasiun penelitian. Hal ini relevan dengan ditemukannya koloni karang dewasa dari jenis-jenis ini dengan menggunakan metode line intercept transect. Jenis karang ini umum dijumpai pada ekosistem terumbu karang tepi sampai kedalaman 20 meter. 
Penelitian rekrutmen karang yang dilaksanakan selama 3 bulan pengamatan ditemukan 9 jenis planula karang yang menempel di subsrat yang telah disediakan. Jenis-jenis planula karang terdiri dari: Acropora millepora, Acropora palifera, Acropora tenuis, Fungia fungites, Montipora digitata, Pocillopora damicormis, Porites sp, Seriatopora hystrix, dan Stylophora pistillata.

Jenis planula karang ditemukan paling banyak di Stasiun 3 yang memiliki kondisi ekosistem terumbu karang yang paling baik di antara 2 stasiun lain yang diteliti. Kondisi ekositem terumbu karang yang baik akan sangat berpengaruh terhadap proses keberlangsungan hidup karang khususnya dalam reproduksi seksual untuk menghasilkan planula. Kemampuan rekrutmen terumbu karang adalah kemampuan dari suatu koloni individual atau suatu sistem terumbu karang, untuk mempertahankan diri dari dampak lingkungan serta menjaga kemampuan untuk pemulihan dan berkembang (Moberg dan Folke, 1999).

Jenis planula yang paling sedikit ditemukan di Stasiun 2 yang terdiri dari 17 individu karang. Hal ini sangat berkaitan dengan kondisi lingkungan di sekitar Stasiun 2, dimana ditemukan aliran sungai aktif yang akan sangat berpengaruh terhadap ekosistem terumbu karang. Aliran air sungai yang aktif secara langsung akan membawa sedimen dan air tawar yang akan mengurangi potensi optimum daya dukung lingkungan bagi ekosistem terumbu karang. Meningkatnya sedimen akan mematikan karang dan tambahan unsur hara dapat menyebabkan karang ditumbuhi alga yang menjadi pesaing karang dalam hidup (Anonim, 2001). Hal ini disebabkan sedimen yang berlebihan dapat mematikan karang, karena oksigen terlarut dalam air tidak dapat berdifusi masuk ke dalam polip karang (Dahuri, dkk. 1996)

\section{Kelimpahan planula karang}

Jumlah planula karang ditemukan berturut-turut dari Stasiun 3 dengan 59 individu, Stasiun 1 dengan 33 individu, dan Stasiun 3 dengan jumlah terendah yaitu 17 individu planula karang. Kelimpahan planula karang sangat berkaitan dengan kondisi lingkungan pendukung untuk kehidupan karang. Semakin optimal daya dukung lingkungan terhadap karang maka semakin optimal juga pertumbuhan dan perkembangan ekosistem terumbu karang yang terkenal sangat rentan.

Kelimpahan planula karang berkaitan erat dengan keberadaan subsrat yang baik bagi kesuksesan peremajaan karang. Menurut Richmond (1997), lokasi penempelan yang baik bagi planula karang cenderung memiliki karakter: tipe dasar perairan yang stabil dan tidak tersusun oleh sedimen lepasan atau bahan tidak padat; gerakan air yang relatif tenang, meskipun dalam kondisi tertentu arus yang kuat mampu mendorong pertumbuhan; dan kadar garam yang relatif normal berkisar antara $32 \%$ sampai $40 \%$.

Stasiun 1 ditemukan jumlah individu terbanyak 11 individu dan terendah 5 individu miring terhadap datangnya arus (MB). Hal ini berbeda dengan penemuan di Stasiun 2, yang ditemukan paling sedikit planula karang yang menempel, dimana 7 individu pada posisi tegak terhadap membelakangi arus (TB) atau 2 individu ditemukan pada posisi miring membelakangi arus (MB). 


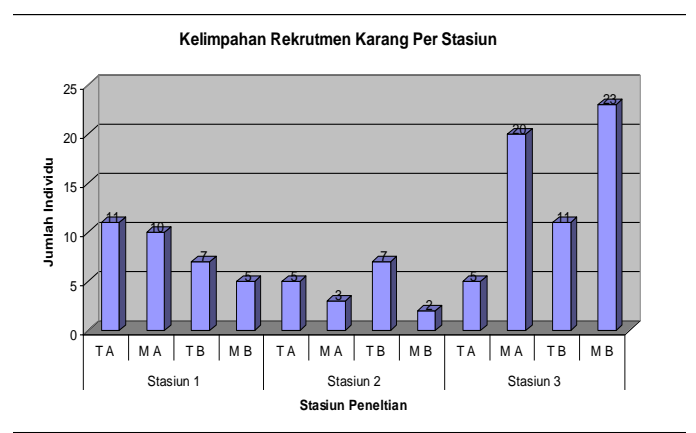

Gambar 4. Kelimpahan Rekrutmen Karang

Kelimpahan individu rekrutmen karang ditemukan dalam jumlah terbanyak, dengan kelimpahan tertinggi di subsrat miring terhadap arus sebanyak 23 individu dan terendah 5 individu pada subsrat tegak terhadap arus.

Adanya sinar matahari yang berperan dalam proses fotosintesis bagi zooxanthellae, sedimentasi terbatas di kolom air untuk mengurangi kemungkinan terhalangnya sinar matahari dan ketiadaan alga mikro yang mampu bersaing tempat dengan karang dan membatasi penempelan larva.

\section{Pola bertahan hidup planula karang}

Pada Gambar 4. memperlihatkan bahwa, kelimpahan planula karang Stasiun 1 ditemukan 11 individu di posisi tegak terhadap arus (TA) dan terendah 5 individu miring terhadap datangnya arus (MB). Hal ini berbeda dengan penemuan di Stasiun 2, yang ditemukan paling sedikit planula karang yang menempel, dimana 7 individu pada posisi tegak terhadap membelakangi arus (TB) atau 2 individu ditemukan pada posisi miring membelakangi arus (MB). Kelimpahan individu rekrutmen karang ditemukan dalam jumlah terbanyak, dengan kelimpahan tertinggi di subsrat miring terhadap arus sebanyak 23 individu dan terendah 5 individu pada subsrat tegak terhadap arus.
Pola bertahan hidup planula karang yang menyangkut pertumbuhan dan perkembangan planula sangat berkaitan faktor-faktor pembatas optimal bagi karang seperti cahaya matahari. Hal ini terlihat dari penyebaran planula yang ditemukan di semua stasiun penelitian yang merupakan daerah dengan paparan sinar matahari sepanjang tahun. Menurut Supriharyono (2000), cahaya matahari bersama-sama dengan zooxanthellae merupakan faktor lingkungan yang mengontrol distribusi vertikal karang dan laju pembentukan (kalsifikasi) terumbu karang oleh individu dari setiap koloni. Cahaya diperlukan untuk fotosintesis alga simbiosis yaitu zooxanthellae yang produksinya kemudian disumbangkan kepada hewan karang yang menjadi inangnya.

Faktor suhu sangat berperan dalam pola bertahan hidup planula, pada awal penelitian ditemukan sejumlah banyak planula yang mulai menempel tetapi dalam perkembangannya hanya sedikit yang bertahan. Perkembangan terumbu karang yang paling optimal jika rata-rata suhu tahunannya $23-25^{\circ} \mathrm{C}$ dan mendekati kondisi tropis. Suhu mempunyai peranan penting dalam membatasi sebaran terumbu karang, karena karang hermatypik sebagai komponen utama penyusunnya memiliki pertumbuhan optimal pada suhu rata-rata di atas $20^{\circ} \mathrm{C}$ sepanjang tahunnya (Barner dan Hughes, 1990).

Kedalaman yang dipakai dalam penelitian ini adalah pada kedalaman 5 meter disetiap stasiun penelitian, kedalaman ini merupakan kedalaman yang diujikan untuk melihat pertumbuhan planula karang untuk menjadi koloni karang. Hal ini dimaksudkan untuk melihat pengaruh faktor dari daratan dan laut dalam pertumbuhan dan perkembangan planula. Menurut 
Supriharyono (2000), secara umum kedalaman yang masih layak untuk pertumbuhan karang adalah berkisar antara 10 - 15m. Ditlev (1980), menyatakan bahwa karang menurun pertumbuhannya dengan bertambahnya kedalaman perairan. Jika air keruh, karang hanya dapat tumbuh pada kedalaman 2 meter. Sedangkan pada air yang jernih biru di sekitar pulau-pulau samudera, karang dapat tumbuh sampai pada kedalaman lebih dari 80 meter.

Secara umum terumbu karang tidak dapat berkembang dengan baik pada perairan yang lebih dalam dari 50-70 meter. Menurut Nybakken (1992), semakin berkurangnya cahaya berdampak pada menurunkan kemampuan laju fotosintesis zooxanthellae, sehingga kemampuan mendepositkan kalsium karbonat dan membentuk terumbupun akan berkurang. Hal ini ditunjukkan dengan terbatasnya struktur terumbu di pinggiran benua-benua atau pulau-pulau.

Pertumbuhan dan perkembangan planula karang sangat tergantung pada salinitas air laut. Hal ini terlihat pada Stasiun 2 yang memiliki koneksi dengan air tawar secara langsung, dimana terdapat sungai aktif di kawasan ini. Salinitas rendah pada umumnya sangat mempengaruhi distribusi maupun zonasi terumbu karang. Terumbu karang dapat berkembang optimal pada kawasan dengan salinitas yang normal bagi kondisi perairan laut (Nybakken, 1992). Terumbu karang tidak dapat berkembang pada kawasan pantai yang secara periodik mendapat masukan air sungai, dan ini merupakan faktor utama yang mempengaruhi distribusi karang sepanjang garis pantai. Hal ini disebabkan karang hermatipik adalah organisme laut sejati yang tidak akan dapat hidup jika kadar salinitas menyimpang dari normal $32-35 \%$.
Stasiun penelitian 2 juga mendapat paparan dari sungai yang membawa air tawar dan sedimen yang menyebabkan kekeruhan, sehingga terlihat pola bertahan hidupnya lebih cenderung berada di level atas subsrat penelitian. Kekeruhan air dapat mengurangi intensitas cahaya masuk dan dapat menyebabkan terganggu sampai matinya terumbu karang. Sedimentasi secara langsung dan tidak langsung mempengaruhi pertumbuhan karang karena banyaknya energi yang dikeluarkan untuk menghalau sedimen ini agar tidak ke permukaan polip. Meningkatnya sedimen akan mematikan karang dan tambahan unsur hara dapat menyebabkan karang ditumbuhi alga yang menjadi pesaing karang dalam hidup. Hal ini disebabkan sedimen yang berlebihan dapat mematikan karang, karena oksigen terlarut dalam air tidak dapat berdifusi masuk ke dalam polip karang.

\section{SIMPULAN DAN SARAN Simpulan}

Penyebaran planula karang ditemukan pada semua stasiun penelitian dengan penyebaran terbesar pada Stasiun 3 sebanyak 59 individu dan terendah di Stasiun 2 sebanyak 17 individu.

Planula karang yang ditemukan terdiri dari jenis 9 karang dan 109 individu, terdiri dari: Acropora millepora, Acropora palifera, Acropora tenuis, Fungia fungites, Montipora digitata, Pocillopora damicormis, Porites sp, Seriatopora hystrix, dan Stylophora pistillata.

Kondisi fisik, kimia, dan biologis perairan di Kawasan Wisata Lovina relatif masih mendukung pertumbuhan dan perkembangan planula karang untuk dapat menjadi koloni karang 


\section{Saran}

Diperlukan suatu kesepakatan bersama yang melibatkan masyarakat dan berdasarkan data-data ilmiah, tentang zona pemanfaatan sumberdaya pesisir di Kawasan Lovina yang lestari, bertanggungjawab, dan berkelanjutan.

Penelitian tentang rekrutmen karang dengan menggunakan rancangan bangun rekrutmen karang sangatlah diperlukan sebagai data dasar pengelolaan kawasan ekosistem terumbu karang, sehingga diperlukan penelitian lanjutan dari pola rekrutmen karang dalam upaya recovery terumbu karang Kawasan Lovina

Mengingat masih banyaknya misteri dan keunikan di ekosistem terumbu karang yang kita miliki sendiri, hendaknya dibudayakan kecintaan pada lingkungan pesisir dan lautan untuk berani ke laut.

\section{DAFTAR PUSTAKA}

Allen, G. R. and Roger Steene. 1999. IndoPasific Coral Reef Field Guide. Tropical Reef Research. California.

Anonim 2002 "Reefs at Risk Southeast AsiaSummary for Indonesia" Terumbu Karang yang Terancam di Asia Tenggara-Ringkasan untuk Indonesia, World Research Institute (WRI) www.wri.org/wri/reefsatrisk )

Barnes, R. S. K. and Hughes. 1990. An Introduction to Marine Ecology. Blacwell Scientific Publisher. London.

Clark, S. 2000. Evaluation of Succession on Coral Recruitment in Maldives. Departement of Marine Sciences and Coastal Management, University of Newcastle. UK.

English, S.C. Wilkinson, and v. Baker, 1994. Survey Manual for Tropical Marine Resources, Australia Institute of Marine Science. Townsville.

Faizal, Ahmad. 2001. Pererapan Teknik Penginderaan Jauh dan Sistem Informasi Geografis untuk
Penyusunan Tata Ruang Ekosistem Terumbu Karang di Pulau Tanakeke Sulawesi Selatan (tesis). Jurusan Matematika dan IImu Pengetahuan Alam, Program Studi Penginderaan Jauh, Program Pascasarjana Universitas Gadjah Mada. Yogyakarta.

Gomez, E.D and H.T. Yap. 1988. Monitoring Reef Conditions. In: Kenchington, R.A and B. E. T. Hudson (eds). Coral Reef Management Handbook. Unesco Regional Office for Science and Technology for South-East Asia. Jakarta.

Morita, M., Akira Iguchi, Akihiro Takemura. 2010. Roles of Calmodulin and Calcium/Calmodulin-Dependent Protein Kinase in Flagellar Motility Regulation in the Coral Acropora Digitifera Marine Biotecnology Journal. Springer Verlag UK.

Morton, J. 1990. The Shore Ecology of The Tropical Pasific. Unesco Regional Office for Science and Technology for South East Asia. Jakarta.

Prasetia, I. N. D. 2001. Struktur Komunitas Karang di Nusa Lembongan, Nusa Penida, Klungkung (skripsi). Jurusan Biologi, Fakultas Matematika dan IImu Pengetahuan Alam, Universitas Udayana.

Prasetia, I. N. D. 2007. Study of Coral Recruitment in Nusa Lembongan Island, Nusa Penida, Klungkung, Bali (tesis). Marine Biology and Fisheries Concentration. Magister IImu Lingkungan, Universitas Udayana. Denpasar.

Prasetia, I. N. D. 2009. Struktur Komunitas Terumbu Karang di Pantai Sanur Denpasar, Bali. Jurnal Lingkungan Tropis. Bandung

Prasetia, I. N. D. 2010. Struktur Komunitas Terumbu Karang Pulau Serangan Pasca Reklamasi. Jurnal Lingkungan Tropis. Bandung

Prasetia, I. N. D. 2010. Potensi dan Kondisi Terumbu Karang di Kawasan Wisata 
Lovina. Universitas Pendidikan

Ganesha. Singaraja

Ranjbar. M. S. 2010. Coral mortality and serpulid infestations with red tide, in the Persian Gulf. Marine Biotecnology Journal. Springer Verlag. UK.

Sunarta, I. N., I Ketut Sudiarta, I Wayan Restu, I Made Adikampana. 2003.

Neraca Sumber Daya Alam Spasial Daerah Propinsi Bali Tahun 2003. Kerjasama Badan Perencanaan Pembangunan Daerah Propinsi Bali dengan Laboratorium Perencanaan dan Pengembangan Pariwisata Universitas Udayana. Denpasar.

Warner, G. F. 1984. Diving and Marine Biology, The Ecology of the Sublittoral. Cambridge University Press. 